\title{
Associação entre a infecção pelo SARS-CoV-2 e o aparecimento de manifestações orais: uma revisão sistemática
}

Association between SARS-CoV-2 infection and the appearance of oral manifestations: a systematic review

Asociación entre la infección por SARS-CoV-2 y la aparición de manifestaciones orales: una revisión sistemática

Resumo

O objetivo desta revisão sistemática qualitativa é estabelecer a relações entre a infecção pelo SARS-CoV-2 e o aparecimento de manifestações bucais. Os resultados foram obtidos após extensa pesquisa e revisão de artigos atualmente publicados sobre o tema em questão. Estudos apontam que a mucosa da cavidade oral pode ser uma rota de alto risco para a infecção pelo SARS-CoV-2, levantando a hipótese de que lesões podem se desenvolver na cavidade bucal em decorrência da infecção pelo vírus. As alterações mais comumente relatadas são os distúrbios do paladar, como disgeusia, hipogeusia e ageusia. Lesões de mucosa, como úlceras, erosões, mucosites, bolhas, máculas e placas, também foram encontradas em pacientes acometidos, variando em quantidade, aparência de cor e localização. Sensação de boca seca, alterações na ATM e infecções virais e fúngicas oportunistas foram relatadas em alguns casos. No entanto, ainda não está clara a relação direta de causa e efeito entre a infecção pelo SARS-CoV-2 e o aparecimento de lesões na cavidade bucal. Autores defendem que o estado geral de imunossupressão, estresse e/ou alterações vasculares, inerentes à doença COVID-19, podem explicar o aparecimento dessas lesões. É evidente, portanto, que existe uma relação entre COVID-19 e o desenvolvimento de lesões bucais, porém mais estudos são necessários para entender a patogenia dessas alterações.

Palavras-chave: Coronavírus; COVID-19; Manifestações orais.

\begin{abstract}
The aim of this qualitative systematic review is to establish the relationship between SARS-CoV-2 infection and the appearance of oral manifestations. The results were obtained after extensive research and review of articles currently published on the subject in question. Studies claim that the mucosa of the oral cavity may be a high-risk route for SARS-CoV-2 infection, raising the hypothesis that lesions may develop in the oral cavity due to the virus infection. The most commonly reported changes are taste disorders such as dysgeusia, hypogeusia and ageusia. Mucous lesions, such as ulcers, erosions, mucositis, blister, macules and plaques, also found in affected patients, varying in quantity, appearance and location. Dry mouth sensation, TMJ disorders and opportunistic fungal and viral infections are reported in some cases. However, the direct cause-and-effect relationship between SARS-CoV-2 infection and the appearance of lesions in the oral cavity is still unclear. Authors defend that the general state of immunosuppression, stress and/or vascular alterations, inherent to COVID-19, may explain the arise these lesions. It is evident, therefore, that there is a relationship between COVID-19 and the development of dental lesions, but further studies are needed to understand the pathogenesis of these alterations.
\end{abstract}

Keywords: Coronavirus; COVID-19; Oral manifestations. 


\begin{abstract}
Resumen
El objetivo de esta revisión sistemática cualitativa es establecer la relación entre la infección capilar SARS-CoV-2 y la aparición de manifestaciones orales. Los resultados se obtuvieron tras una extensa investigación y revisión de los artículos publicados actualmente sobre el tema en cuestión. Los estudios afirman que la mucosa de la cavidad oral puede ser una ruptura de alto riesgo para la infección capilar SARS-CoV-2, lo que plantea la hipótesis de que se pueden desarrollar lesiones en la cavidad oral debido a la infección por virus capilar. Los cambios notificados con más frecuencia son trastornos del paladar como disgeusia, hipogeusia y ageusia. Las lesiones mucosas, como úlceras, erosiones, mucositis, proyectiles, máculas y placas, también se encuentran en los pacientes afectados, variando en cantidad, apariencia corporal y ubicación. En algunos casos se informan sensación de sequedad en la boca, cambios en la ATM e infecciones fúngicas y virales oportunistas. Sin embargo, la relación directa de causa y efecto entre la infección capilar por SARS-CoV-2 y la aparición de lesiones en la cavidad oral aún no está clara. Los autores defienden que el estado general de inmunosupresión, estrés y / o alteraciones vasculares, inherentes al COVID-19, pueden explicar o dar origen a estas lesiones. Es evidente, por tanto, que existe una relación entre el COVID-19 y el desarrollo de lesiones dentales, por lo que se necesitan más estudios para comprender la patogenia de estas alteraciones.
\end{abstract}

Palavras clave: Coronavirus; COVID-19; Manifestaciones orales.

\title{
1. Introdução
}

Desde que se registraram os primeiros casos de pneumonia associados ao novo Coronavírus (denominado mais tarde como SARS-CoV-2), em dezembro de 2019, as infecções se deram de maneira bastante rápida e em poucas semanas a doença passou a ser considerada pela OMS como uma pandemia (Bertolini et al., 2002). A propagação mundial da COVID-19 fez com que os profissionais da saúde descobrissem uma série de alterações que a doença pode causar (Pedrosa et al.,2020). Muitas manifestações de infecção por SARS-CoV-2 foram descritas na literatura até o momento (Lechien et al., 2020). Os sinais e os sintomas mais comuns relatados foram dor de cabeça, dor de garganta, hiposmia, hipogeusia, diarreia, dispneia e pneumonia (Sandhaus et al.,2020). Alguns autores também descreveram casos com manifestações dermatológicas (Sinadinos et al., 2020).

A cavidade oral é considerada por especialistas uma abertura para a entrada de muitos microrganismos, por apresentar características bastante propícias para o desenvolvimento dos mesmos, como a temperatura e a umidade, que facilitam a sua permanência (Pedrosa et al., 2020). Além disso, a boca é a principal fonte de transmissão de infecções, incluindo graves síndromes respiratórias agudas, como a COVID-19 (Orcina et al., 2021).

$\mathrm{O}$ vírus SARS-CoV-2 usa proteína spike (SP) para se ligar à membrana celular e invadir as células do hospedeiro, um processo ativado por enzimas celulares específicas (Sakaguchi et al., 2020). O receptor mais comum para a entrada viral é a enzima conversora de angiotensina II (ACE2), que pode ser encontrada em altas concentrações nos pulmões, células miocárdicas e renais, bem como nas células da mucosa oral, especialmente na língua e glândulas salivares (Orcina et al.,2021). Essas descobertas indicam que a mucosa da cavidade oral pode ser uma rota de alto risco para a infecção pelo SARS-CoV-2 (Xu et al., 2020).

Diante do exposto, o presente artigo possui como objetivo revisar a literatura, de forma sistêmica, acerca das manifestações orais causadas pela infecção pelo vírus SARS-CoV-2 e apontar quais são os sinais e sintomas mais comuns nesses pacientes, bem como associar a patogênese da infecção viral com as alterações na mucosa bucal, tentando explicar seus mecanismos.

\section{Metodologia}

Para esclarecer a associação entre a infecção pelo SARS-CoV-2 e o aparecimento de lesões na mucosa bucal, foram pesquisados artigos científicos nas bases de dados SciELO, BVS, LILACS, PubMed e Elsevier. A busca eletrônica de artigos foi realizada em julho de 2021 a partir das palavras-chave "COVID-19"; "SARS-CoV-2" e "oral”. A conjunção aditiva "e" e "and" (no inglês) foi acrescentada para fornecer o sentido de relação entre os termos. Foram incluídos trabalhos que se encontrem publicados em língua inglesa e portuguesa nos anos de 2020 e 2021. A seleção dos artigos foi feita inicialmente pela leitura dos 
seus títulos. Posteriormente os resumos / abstracts foram lidos e avaliados, sendo os critérios de inclusão: artigos que se apresentem dentro do tema proposto, com metodologia confiável e que contenham dados consistentes. Textos com informações incompletas ou cujo conteúdo não se adequa à presente revisão foram descartados. Finalmente os artigos restantes foram lidos na íntegra, sendo selecionados aqueles que se enquadraram na pesquisa. Dos 44 artigos localizados na busca geral, 27 publicações foram selecionadas para compor esta revisão, após análise criteriosa (Figura 1).

Figura 1: Fluxograma da filtragem dos artigos.

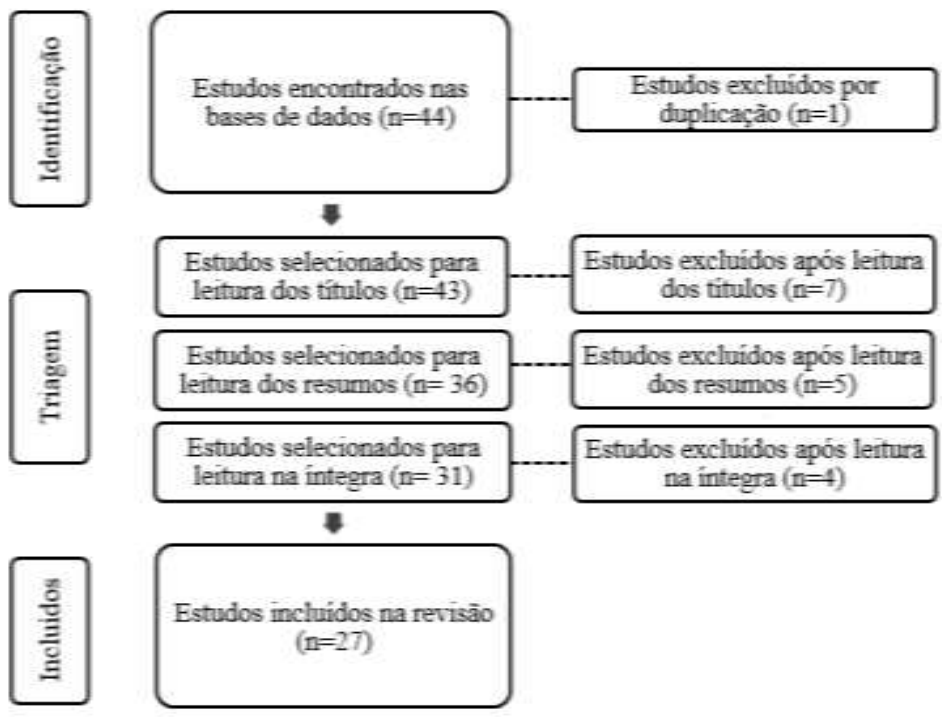

Fonte: Autores.

\section{Resultados}

De acordo com o Protocolo de Manejo Clínico para o Novo Coronavírus, publicado pelo Ministério da Saúde, na avaliação dos primeiros 99 pacientes internados com pneumonia e diagnóstico laboratorial de COVID-19 no hospital de Wuhan, os principais sintomas observados foram: febre (83\%), tosse (82\%), dispneia (31\%), mialgia (11\%), confusão mental (9\%), cefaleia $(8 \%)$, dor de garganta $(5 \%)$, rinorreia $(4 \%)$, dor torácica $(2 \%)$, diarreia $(2 \%)$ e náuseas e vômitos $(1 \%)$. Também houveram registros de linfopenia (Lima., 2020).

As manifestações cutâneas e bucais da COVID-19 vêm sendo relatadas por diversos autores. Em um estudo com 88 pacientes infectados, foi observado que 20,4\% apresentaram manifestações cutâneas, como erupção eritematosa, urticária generalizada e vesículas (Rocha et al., 2021). As alterações de mucosa são bastante variadas, tanto no tipo de lesão quanto em suas quantidades, aparências clínicas e localizações. As manifestações mais frequentes são descritas a seguir, a partir da coleta de dados listada no Quadro 1. 
Quadro 1: Estudos selecionados para a pesquisa.

\begin{tabular}{|c|c|c|c|}
\hline Citação & Tipo de Artigo & Objetivos & Principais resultados \\
\hline $\begin{array}{l}\text { Aghzedeh et } \\
\text { al., } 2020\end{array}$ & Carta ao editor & $\begin{array}{l}\text { Descrever as manifestações bucais } \\
\text { em uma paciente do sexo feminino } \\
\text { de } 09 \text { anos de idade infectada com o } \\
\text { vírus SARS-CoV- } 2 \text {. }\end{array}$ & $\begin{array}{l}\text { A paciente apresentou vesículas e erosões } \\
\text { envolvendo os lábios e região anterior da língua } \\
\text { durante a infecção. }\end{array}$ \\
\hline $\begin{array}{l}\text { Biadsee et } \\
\text { al., } 2020\end{array}$ & Série de casos & $\begin{array}{l}\text { Avaliar os sinais e sintomas de } 140 \\
\text { pacientes ambulatoriais de COVID- } \\
\text { 19, associando-os com o sexo. }\end{array}$ & $\begin{array}{l}56 \% \text { dos pacientes apresentaram xerostomia e } \\
32,8 \% \text { perda de paladar, além dos sintomas clássicos } \\
\text { da COVID-19. Anosmia e dor facial foram mais } \\
\text { comuns entre as mulheres. }\end{array}$ \\
\hline $\begin{array}{l}\text { Brandão et } \\
\text { al., } 2020\end{array}$ & Série de casos & $\begin{array}{l}\text { Avaliar os sinais e sintomas de } 8 \\
\text { pacientes e revisar brevemente a } \\
\text { literatura sobre a ação da ACE2 na } \\
\text { infecção pelo SARS-CoV-2. }\end{array}$ & $\begin{array}{l}\text { Os } 8 \text { casos apresentaram úlceras e lesões aftosas que } \\
\text { se desenvolveram no início da doença e afetaram a } \\
\text { língua, os lábios, o palato e a orofaringe. A ACE2 é } \\
\text { o principal receptor celular para a entrada do vírus } \\
\text { SARS-CoV-2 e está presente nas células da mucosa } \\
\text { oral. }\end{array}$ \\
\hline $\begin{array}{l}\text { Carreras- } \\
\text { Presas et al., } \\
2020\end{array}$ & $\begin{array}{l}\text { Comunicado } \\
\text { breve }\end{array}$ & $\begin{array}{l}\text { Descrever as manifestações bucais } \\
\text { de } 2 \text { pacientes com suspeita de } \\
\text { COVID-19 e } 1 \text { paciente com } \\
\text { confirmação da infecção. }\end{array}$ & $\begin{array}{l}\text { Dois pacientes apresentaram lesões ulceradas na } \\
\text { mucosa do palato e um paciente apresentou lesão } \\
\text { vesico-bolhosa na região do lábio inferior. }\end{array}$ \\
\hline $\begin{array}{l}\text { Chaux- } \\
\text { Bodard et } \\
\text { al., } 2020\end{array}$ & Carta ao editor & $\begin{array}{l}\text { Descrever as manifestações bucais } \\
\text { de uma paciente de } 45 \text { anos do sexo } \\
\text { feminino, sendo uma possível } \\
\text { manifestação inicial da COVID-19. }\end{array}$ & $\begin{array}{l}\text { A paciente se queixou de uma úlcera irregular e } \\
\text { dolorosa no dorso da língua, que desapareceu após } \\
10 \text { dias, sugerindo um possível sinal inicial da } \\
\text { infecção pelo SARS-CoV-2. }\end{array}$ \\
\hline $\begin{array}{l}\text { Chen et al., } \\
2020\end{array}$ & $\begin{array}{l}\text { Estudo } \\
\text { Original }\end{array}$ & $\begin{array}{l}\text { Avaliar a presença de ACE2 nas } \\
\text { glândulas salivares, através da } \\
\text { análise de RNA de } 31 \text { pacientes com } \\
\text { COVID-19. }\end{array}$ & $\begin{array}{l}\text { Foi encontrada expressão de ACE2 nas glândulas } \\
\text { salivares dos pacientes analisados, demonstrando a } \\
\text { possibilidade de infecção por SARS-CoV-2 nas } \\
\text { glândulas salivares. }\end{array}$ \\
\hline $\begin{array}{l}\text { Corchuelo } \\
\& \quad \text { Ulloa, } \\
2020\end{array}$ & Relato de caso & $\begin{array}{l}\text { Avaliar as manifestações bucais de } \\
\text { uma paciente de } 40 \text { anos do sexo } \\
\text { feminino com COVID- } 19 \text {. }\end{array}$ & $\begin{array}{l}\text { A paciente apresentou petéquias no lábio inferior, } \\
\text { aftas na borda lateral de língua e gengiva inserida. } \\
\text { Manchas esbranquiçadas no dorso da língua e } \\
\text { sensação de boca seca levaram ao diagnóstico } \\
\text { presuntivo de candidíase oral leve associada a } \\
\text { COVID-19. }\end{array}$ \\
\hline Filette, 2020 & Relato de caso & $\begin{array}{l}\text { Avaliar as manifestações cutâneas } \\
\text { de uma mulher de } 35 \text { anos com } \\
\text { sinais e sintomas de COVID- } 19 \text {. }\end{array}$ & $\begin{array}{l}\text { A paciente apresentou ulceração acima do lábio } \\
\text { superior e inflamação na língua, com sinais } \\
\text { semelhantes a Doença de Kawasaki. É possível que } \\
\text { haja associação entre COVID-19 e Doença de } \\
\text { Kawasaki. }\end{array}$ \\
\hline $\begin{array}{l}\text { Lechien, } \\
2020\end{array}$ & Série de casos & $\begin{array}{l}\text { Relatar as características clínicas de } \\
3 \text { pacientes com inflamação da } \\
\text { glândula parótida associadas à } \\
\text { COVID-19. }\end{array}$ & $\begin{array}{l}3 \text { pacientes tiveram manifestação similar a parotidite } \\
\text { como sinal clínico da COVID-19. Exames de } \\
\text { ressonância magnética mostram a ocorrência de } \\
\text { linfadenite intraparotídea nesses pacientes. }\end{array}$ \\
\hline Lima, 2020 & $\begin{array}{l}\text { Comunicado } \\
\text { breve }\end{array}$ & $\begin{array}{l}\text { Apresentar informações sobre o } \\
\text { vírus SARS-CoV-2 e as principais } \\
\text { características de sua infecção. }\end{array}$ & $\begin{array}{l}\text { A infecção pelo SARS-CoV-2 pode variar de um } \\
\text { simples resfriado até uma pneumonia grave, sendo } \\
\text { os sinais e sintomas mais comuns: febre, tosse seca, } \\
\text { fadiga, produção de escarro, dispneia, dor de } \\
\text { garganta e cefaleia. Casos assintomáticos também } \\
\text { são reportados. }\end{array}$ \\
\hline $\begin{array}{l}\text { Lowe et al., } \\
2021\end{array}$ & Relato de caso & $\begin{array}{l}\text { Descrever os sinais e sintomas de } \\
\text { um paciente de } 46 \text { anos do sexo } \\
\text { masculino com infecção pelo SARS- } \\
\text { CoV-2. }\end{array}$ & $\begin{array}{l}\text { O paciente apresentou múltiplas úlceras cobertas por } \\
\text { membrana amarelo-acinzentada na mucosa oral, } \\
\text { sendo diagnosticado com gengivoestomatite } \\
\text { herpética associada a COVID-19. }\end{array}$ \\
\hline
\end{tabular}




\begin{tabular}{|c|c|c|c|}
\hline $\begin{array}{l}\text { Malih et al., } \\
2020\end{array}$ & Série de casos & $\begin{array}{l}\text { Descrever as manifestações em um } \\
\text { paciente de } 38 \text { anos do sexo } \\
\text { masculino com resultado do teste } \\
\text { PCR positivo para COVID-19. }\end{array}$ & $\begin{array}{l}\text { Foi observada lesão aftosa na amígdala esquerda, } \\
\text { além de erupção cutânea e perda do paladar e do } \\
\text { olfato durante a infecção pelo SARS-CoV- } 2 \text {. }\end{array}$ \\
\hline $\begin{array}{l}\text { Medeiros et } \\
\text { al., } 2020\end{array}$ & $\begin{array}{l}\text { Estudo } \\
\text { transversal }\end{array}$ & $\begin{array}{l}\text { Avaliar a prevalência de sintomas de } \\
\text { DTM, ansiedade e depressão durante } \\
\text { o isolamento social no contexto da } \\
\text { pandemia de COVID-19. }\end{array}$ & $\begin{array}{l}27,4 \% \text { dos participantes infectados pelo vírus da } \\
\text { COVID-19 relataram dor na Articulação } \\
\text { Temporomandibular, além de alta prevalência de } \\
\text { sintomas de ansiedade e depressão nesse grupo. }\end{array}$ \\
\hline $\begin{array}{l}\text { Miranda et } \\
\text { al., } 2021\end{array}$ & $\begin{array}{l}\text { Revisão } \\
\text { sistemática }\end{array}$ & $\begin{array}{l}\text { Discutir como a pandemia } \\
\text { COVID-19 pode influenciar } \\
\text { surgimento, manutenção } \\
\text { agravamento da DTM. }\end{array}$ & $\begin{array}{l}\text { Durante a pandemia de COVID-19 houve aumento } \\
\text { da manifestação de hábitos parafuncionais orais } \\
\text { inconscientes, má qualidade do sono e } \\
\text { automedicação. Todos esses fatos representam } \\
\text { fatores de risco comuns à DTM. }\end{array}$ \\
\hline $\begin{array}{l}\text { Moraes et } \\
\text { al., } 2021\end{array}$ & $\begin{array}{l}\text { Revisão } \quad \text { da } \\
\text { literatura }\end{array}$ & $\begin{array}{l}\text { Relatar as manifestações bucais e } \\
\text { cutâneas da COVID-19 em } \\
\text { pacientes pediátricos. }\end{array}$ & $\begin{array}{l}\text { As manifestações bucais e cutâneas mais citadas } \\
\text { foram, respectivamente, a disfunção gustativa em } \\
\text { adolescentes e a erupção eritematosa em } \\
\text { extremidades e tronco. }\end{array}$ \\
\hline $\begin{array}{l}\text { Nuno- } \\
\text { Gonzalez et } \\
\text { al., } 2021\end{array}$ & Carta ao editor & $\begin{array}{l}\text { Avaliar as manifestações muco } \\
\text { cutâneas de } 666 \text { pacientes com teste } \\
\text { PCR positivo para COVID- } 19 \text {. }\end{array}$ & $\begin{array}{l}45,7 \% \text { dos pacientes apresentaram uma ou mais } \\
\text { manifestações muco cutâneas e } 25,7 \% \text { manifestaram } \\
\text { alterações na cavidade bucal, incluindo papilite } \\
\text { lingual, glossite, estomatite aftosa, mucosite, } \\
\text { sensação de queimação na boca e disgeusia. }\end{array}$ \\
\hline $\begin{array}{l}\text { Orcina \& } \\
\text { Santos, } \\
2021\end{array}$ & Série de casos & $\begin{array}{l}\text { Avaliar as manifestações bucais de } \\
11 \text { pacientes positivos para COVID- } \\
19 \text { por teste PCR e IgM e reportar a } \\
\text { ação do Phtalox }{ }^{\circledR} \text { no tratamento } \\
\text { dessas lesões. }\end{array}$ & $\begin{array}{l}\text { Cinco pacientes apresentaram úlceras bucais e foram } \\
\text { orientados a fazer uso de enxaguatório Phtalox }{ }^{\circledR} \text { por } \\
1 \text { min, cinco vezes ao dia. A cura completa das } \\
\text { úlceras ocorreu em todos os pacientes em média } \\
\text { após } 2,37 \text { dias. O estudo sugere associação entre } \\
\text { infecção pelo COVID-19 e o aparecimento de } \\
\text { úlceras bucais. O tratamento se mostrou eficaz. }\end{array}$ \\
\hline $\begin{array}{l}\text { Pedrosa et } \\
\text { al., } 2020\end{array}$ & $\begin{array}{l}\text { Revisão de } \\
\text { literatura }\end{array}$ & $\begin{array}{l}\text { Revisar a literatura sobre a saliva e } \\
\text { as glândulas salivares no contexto da } \\
\text { infecção pelo SARS-CoV-2 e } \\
\text { apresentar uma breve discussão } \\
\text { sobre os distúrbios bucais } \\
\text { encontrados durante a infecção pelo } \\
\text { vírus. }\end{array}$ & $\begin{array}{l}\text { Há evidências que o SARS-CoV-2 pode infectar as } \\
\text { glândulas salivares e estar presente na saliva. } \\
\text { Pacientes com COVID-19 apresentaram } \\
\text { repercussões bucais como hipossalivação, alterações } \\
\text { do paladar, úlceras e bolhas. }\end{array}$ \\
\hline $\begin{array}{l}\text { Rocha et al., } \\
2021\end{array}$ & Carta ao editor & $\begin{array}{l}\text { Avaliar a presença enantema bucal } \\
\text { em pacientes com COVID-19 como } \\
\text { um possível desafio ao diagnóstico. }\end{array}$ & $\begin{array}{l}\text { Enantema bucal pode ser uma manifestação da } \\
\text { infecção pelo SARS-CoV-2, como observado em } \\
\text { diversos pacientes. No entanto, essa alteração pode } \\
\text { ser causada também por outros patógenos como os } \\
\text { vírus da Chikungunya, Dengue, Ebola e Herpes. }\end{array}$ \\
\hline $\begin{array}{l}\text { Rodríguez } \\
\text { et al., } 2020\end{array}$ & Carta ao editor & $\begin{array}{l}\text { Reportar } 3 \text { casos de pacientes } \\
\text { testados positivos para COVID-19 } \\
\text { com manifestações bucais. }\end{array}$ & $\begin{array}{l}\text { Queilite angular foi observada em um paciente, } \\
\text { atrofia do dorso da língua com presença de placas } \\
\text { fúngicas brancas e eritema no palato foram descritas } \\
\text { em outra paciente e despapilação lingual seguida de } \\
\text { úlcera foi relatada pela terceira paciente avaliada. As } \\
\text { lesões bucais são desencadeadas frequentemente } \\
\text { pelo estado de imunossupressão causado pela } \\
\text { doença. }\end{array}$ \\
\hline $\begin{array}{l}\text { Sandhaus et } \\
\text { al., } 2020\end{array}$ & $\begin{array}{l}\text { Comunicado } \\
\text { breve }\end{array}$ & $\begin{array}{l}\text { Reportar a doença de Kawasaki } \\
\text { como uma possível nova } \\
\text { manifestação da COVID-19 em } \\
\text { crianças. }\end{array}$ & $\begin{array}{l}\text { Na população pediátrica, novos casos de doença de } \\
\text { Kawasaki com manifestações bucais foram } \\
\text { identificados concomitantemente com a COVID-19. } \\
\text { São necessários mais estudos para avaliar a sua } \\
\text { relação. }\end{array}$ \\
\hline
\end{tabular}




\begin{tabular}{|c|c|c|c|}
\hline $\begin{array}{l}\text { Santos et al., } \\
2020\end{array}$ & $\begin{array}{l}\text { Revisão } \\
\text { sistemática }\end{array}$ & $\begin{array}{l}\text { Resumir os sinais e sintomas orais } \\
\text { em pacientes com COVID- } 19 \text {. }\end{array}$ & $\begin{array}{l}45 \% \text { dos pacientes apresentaram comprometimento } \\
\text { do paladar, sendo o sintoma mais frequente. Lesões } \\
\text { de mucosa oral apresentaram múltiplos aspectos } \\
\text { clínicos, incluindo placas brancas e eritematosas, } \\
\text { úlceras irregulares, pequenas bolhas, petéquias e } \\
\text { gengivite descamativa. Língua, palato, lábios, } \\
\text { gengiva e mucosa bucal foram as regiões mais } \\
\text { afetadas. }\end{array}$ \\
\hline $\begin{array}{l}\text { Sinadinos \& } \\
\text { Shelswell, } \\
2020\end{array}$ & Série de casos & $\begin{array}{l}\text { Avaliar as manifestações bucais de } 1 \\
\text { paciente testado para COVID-19 e } 2 \\
\text { suspeitos. }\end{array}$ & $\begin{array}{l}\text { Os } 3 \text { pacientes apresentaram lesões ulcerativas e } \\
\text { bolhosas na mucosa oral. Os autores sugerem } \\
\text { relação entre as alterações bucais e infecção pelo } \\
\text { SARS-CoV-2. }\end{array}$ \\
\hline $\begin{array}{l}\text { Singh et al., } \\
2020\end{array}$ & Série de casos & $\begin{array}{l}\text { Relato de casos de } 4 \text { pacientes com } \\
\text { diagnóstico de COVID-19 que } \\
\text { desenvolveram lesões cutâneas e } \\
\text { mucosas. }\end{array}$ & $\begin{array}{l}\text { Os pacientes apresentaram lesões na pele, mucosa } \\
\text { das narinas, língua, lábios e uretra. Iniciaram como } \\
\text { uma inflamação e progrediram para uma escara. A } \\
\text { extensão das lesões muco cutâneas sugere um } \\
\text { processo inflamatório vascular no contexto da } \\
\text { infecção pelo SARS-CoV-2. }\end{array}$ \\
\hline $\begin{array}{l}\text { Soares et al., } \\
2020\end{array}$ & Carta ao editor & $\begin{array}{l}\text { Descrever as alterações clínicas e } \\
\text { microscópicas na mucosa oral de um } \\
\text { paciente de } 42 \text { anos do sexo } \\
\text { masculino. }\end{array}$ & $\begin{array}{l}\text { Clinicamente o paciente apresentou uma lesão } \\
\text { avermelhada no palato duro e uma úlcera na mucosa } \\
\text { lingual. A análise histopatológica dos tecidos } \\
\text { demonstrou hiperemia, infiltrado linfocitário no } \\
\text { tecido conjuntivo, trombos e células inflamatórias } \\
\text { no tecido conjuntivo e na camada basal do epitélio } \\
\text { oral. }\end{array}$ \\
\hline $\begin{array}{l}\text { Tapia et al., } \\
2020\end{array}$ & Série de casos & $\begin{array}{l}\text { Descrever as lesões clínico- } \\
\text { patológicas de mucosa bucal em } 4 \\
\text { pacientes com infecção confirmada } \\
\text { por SARS-CoV-2. }\end{array}$ & $\begin{array}{l}\text { Os pacientes apresentaram lesão semelhante a } \\
\text { angina bolhosa hemorrágica e estomatite } \\
\text { inespecífica. } \mathrm{A} \text { análise histológica demonstrou } \\
\text { infiltrado linfocitário perivascular reativo, trombose } \\
\text { capilar focal e hemorragia. Foi estabelecido o } \\
\text { diagnóstico de lesões orais provavelmente } \\
\text { associadas ao COVID-19. }\end{array}$ \\
\hline $\begin{array}{l}\text { Tomo et al., } \\
2020\end{array}$ & Carta ao editor & $\begin{array}{l}\text { Compartilhar um caso de lesões } \\
\text { orais surgidas em uma paciente de } \\
37 \text { anos do sexo feminino com } \\
\text { COVID-19. }\end{array}$ & $\begin{array}{l}\text { A paciente apresentou eritema difuso, petéquias e } \\
\text { despapilação discreta nas bordas da língua, com } \\
\text { sensação de queimação na região e no palato mole. } \\
\text { Não há evidências suficientes para apoiar um dano } \\
\text { da mucosa oral causado pelo SARS-CoV-2, essas } \\
\text { lesões têm maior probabilidade de representar } \\
\text { infecções oportunistas fúngicas, bacterianas e virais } \\
\text { ou reações medicamentosas. }\end{array}$ \\
\hline
\end{tabular}

Fonte: Autores.

\section{1 Úlceras e erosões}

Úlceras orais associadas ao COVID-19 foram mais observadas nos pacientes adultos. Essa alteração foi relatada predominantemente na língua, variando no tamanho, quantidade e sintomatologia. Uma paciente de 45 anos do sexo feminino, diagnosticada com COVID-19, apresentou inicialmente uma lesão eritematosa dolorosa, que evoluiu para uma úlcera assintomática e irregular no dorso da língua. A alteração se resolveu em 10 dias, sem deixar sequelas (Chaux-Bodard et al., 2020). Rodríguez et al. (2020) relataram um caso de lesões aftosas sintomáticas, com sensação de queimação, em paciente de 43 anos positiva para a COVID-19 e com risco de trombose. Após 10 dias de tratamento com triancinolona acetonida 0,05\% as úlceras e os sintomas desapareceram, embora a despapilação da língua tenha persistido. Outro paciente apresentou como possível sintoma inaugural de COVID-19 uma inflamação dolorosa das papilas linguais, que evoluiu para um quadro eritematoso e, 
Research, Society and Development, v. 11, n. 1, e46811125240, 2022

(CC BY 4.0) | ISSN 2525-3409 | DOI: http://dx.doi.org/10.33448/rsd-v11i1.25240

posteriormente, para uma úlcera assintomática (Rocha et al., 2021). Brandão et al. (2020), notificaram uma úlcera de 1,5 cm na borda lateral direita da língua, bem como petéquias e uma área necrótica no palato duro anterior, em paciente feminina de 83 anos de idade. As lesões apresentaram sintomatologia dolorosa, sendo realizada terapia de fotobiomodulação, controlando totalmente a dor após 5 dias.

Embora tenham sido registradas com menor frequência, outras áreas de mucosa também foram acometidas. Lesões vesico-bolhosas e ulceradas foram observadas em três pacientes por Carreras-Presas et al. (2020), presentes no palato e lábios, similares clinicamente a outros processos virais, como a doença das mãos, pés e boca e a gengivoestomatite herpética. Malih et al. (2020) reportam lesões eritematosas e aftosas na tonsila palatina de paciente PCR positivo para SARS-CoV-2, associado à perda de olfato e paladar. Em outro estudo, uma mulher de 35 anos foi internada após de 4 dias de sintomas. A mesma apresentou lábios rachados com ulceração acima do lábio superior (Filette, 2020).

Brandão et al. (2020) notificaram uma série de casos de lesões ulceradas em pacientes positivos para COVID-19. Úlcera rasa, com padrão circular, coberta por membrana fibrinopurulenta e rodeada por um eritema no pilar amigdaliano, causando odinofagia leve, foi relatada em um homem de 35 anos. Um paciente de 28 anos, masculino, com quadro de anosmia e ageusia desenvolveu úlceras aftosas na mucosa labial superior e inferior depois de 8 dias do teste positivo para RNA de SARS-CoV-2. Após 2 dias, outra úlcera foi observada na borda lateral direita da língua no mesmo paciente. Úlcera dolorosa no ventre da língua coberta por pseudomembrana e envolta por halo eritematoso foi observada no sexto dia da fase sintomática de um paciente de 29 anos do sexo masculino, com anosmia e ageusia.

Apesar de as informações sobre manifestações bucais em crianças ainda serem escassas, Aghazadeh et al. (2020) relatam um caso de vesículas e erosões envolvendo os lábios e região anterior da língua em criança de 9 anos infectada com o vírus.

\subsection{Mucosites}

Casos de inflamação da mucosa bucal têm sido relatados em associação à infecção pelo SARS-CoV-2. Uma mulher de 37 anos de idade apresentou eritema difuso, petéquias e despapilação discreta nas bordas da língua, com sensação de queimação na região e no palato mole (Tomo et al., 2020). Outro quadro de mucosite inespecífica foi relatado em um homem de 42 anos. O paciente apresentou máculas avermelhadas múltiplas e irregulares no palato duro, com 3 a 4 mm de diâmetro e de consistência endurecida (Tapia et al., 2020).

\subsection{Mudanças no olfato e paladar}

Segundo Santos et al. (2020), a prevalência geral de distúrbios gustativos foi de 45\% dos casos de COVID-19, sendo que $38 \%$ apresentaram disgeusia, $35 \%$ hipogeusia e $24 \%$ ageusia. Os sintomas geralmente têm duração de 15 dias e os pacientes se recuperam totalmente na maioria dos casos. Mudanças no paladar foram percebidas em $53 \%$ dos pacientes norte-americanos com COVID-19, em 50\% dos europeus e em $27 \%$ dos asiáticos. Esse sintoma parece estar mais associado a casos leves e moderados da doença e são mais comuns em mulheres.

Em um estudo realizado, sessenta e sete pacientes (52\% dos casos) apresentaram mudanças no paladar e alguns pacientes relataram uma mudança na percepção de sabor picante, salgado, azedo e doce. Em uma comparação entre homens e mulheres, mudanças de gosto eram mais comuns entre as mulheres, porém sem diferença estatística significativa (Biadsee et al., 2020). As manifestações bucais e cutâneas mais citadas em outro estudo foram, respectivamente, a disfunção gustativa em adolescentes e a erupção eritematosa em extremidades e tronco (Moraes et al., 2021). 


\subsection{Boca seca}

A sensação de secura na boca tem sido relatada por pacientes com COVID-19 de forma relativamente frequente. Geralmente esse sintoma não é uma manifestação isolada, mas se apresenta associada à outras manifestações. Entre os 14 sintomas orais listados por Chen et al. (2020), boca seca (46,3\% no geral, 46,2\% em homens, 46,4\% em mulheres) teve a maior incidência no estudo realizado. $11,1 \%$ dos pacientes $(13,5 \%$ em homens, $8,9 \%$ em mulheres) infectados pelo SARS-CoV-2 apresentaram secura e inflamação da boca. Em outro estudo, uma mulher de 35 anos, além de apresentar ulceração acima do lábio superior, apresentava queixa de boca extremamente seca (Filette, 2020).

\subsection{Disfunções temporomandibulares}

Durante as epidemias o número de pessoas cuja saúde mental é afetada tende a ser maior do que o número de pessoas afetadas pela infecção, uma vez que o medo aumenta os níveis de ansiedade e estresse em indivíduos saudáveis, levando à manifestação de hábitos parafuncionais orais inconscientes e má qualidade do sono. Todos esses fatos representam fatores de risco comuns à DTM (Miranda et al., 2021). Em estudo com participantes infectados pelo vírus da COVID-19, 27,4\% relataram dor na Articulação Temporomandibular (Medeiros et al.,2020).

\subsection{Infecções fúngicas e virais}

Algumas infecções fúngicas e virais oportunistas têm sido relatadas concomitantemente à infecção pelo SARS-CoV-2. Lesões causadas pelo fungo Cândida albicans e pelo vírus herpes simples são as mais comumente descritas, com sinais e sintomas similares à infecção clássica por esses patógenos.

Uma paciente feminina de 78 anos hospitalizada relatou forte sensação de boca seca, sendo diagnosticada com candidíase pseudomembranosa na região de língua e palato e queilite angular, associados a infecção por SARS-CoV-2 (Diaz et al., 2020). Outra paciente do sexo feminino de 40 anos, testada positivo para COVID-19, apresentou petéquias no lábio inferior, aftas na borda lateral de língua e gengiva inserida e manchas esbranquiçadas no dorso da língua, além de sensação de boca seca, com diagnóstico presuntivo de candidíase oral leve (Corchueloa \& Ulloa, 2020).

Brandão et al. (2020) constataram alguns casos de infecção pelo vírus herpes simples (HVS-1) em pacientes acometidos pela COVID-19. Os sinais incluem pequenas ulcerações hemorrágicas e áreas focais de necrose superficial nos lábios e na região anterior do dorso da língua, com sintomatologia dolorosa. Outro paciente adulto de 46 anos de idade foi diagnosticado com gengivoestomatite herpética secundária no contexto da infecção por COVID-19, que mostra uma progressão mais grave da doença com o aumento da idade (Lowe et al., 2021).

\subsection{Outras manifestações}

Em um estudo realizado com 304 indivíduos, 45,7\% dos pacientes portadores de COVID-19 apresentaram uma ou mais manifestações mucocutâneas. Alterações na cavidade oral foram encontradas em 78 casos (25,7\%), incluindo papilite lingual transitória (11,5\%), glossite com endentações laterais $(6,6 \%)$, estomatite aftosa $(6,9 \%)$, glossite com depapilação $(3,9 \%)$ e mucosite (3,9\%). Sensação de queimação na boca foi relatada em 5,3\% dos pacientes, comumente associada a disgeusia (NunoGonzalez et al., 2021). Queilite angular e sensação de queimação na boca, associado a anosmia e disgeusia, foram registradas em paciente de 53 anos do sexo masculino infectado pelo SARS-CoV-2 (Diaz et al., 2020).

Tapia et al. (2020) observaram lesão semelhante a angina bolhosa hemorrágica, que se desenvolveu no palato de uma mulher de 41 anos durante o seu período de isolamento. Uma mácula roxa difusa com 12 mm de diâmetro e uma lesão pápulaplaca de $8 \mathrm{~mm}$, ambas assintomáticas, foram observadas no palato de outra paciente de 51 anos. Lesão bolhosa, roxa e assintomática de $8 \mathrm{~mm}$ de diâmetro na língua foi relatada por uma paciente de 55 anos. 


\section{Discussão}

As manifestações bucais associadas à COVID-19 variam consideravelmente nos seus aspectos clínicos, sendo as alterações mais comuns os distúrbios do paladar, como disgeusia, hipogeusia e ageusia. Lesões orais, como úlceras, bolhas, máculas e placas, também foram encontradas em pacientes acometidos, variando em quantidade, aparência de cor e localização (Santos et al., 2020).

Embora uma relação direta de causa e efeito entre infecção pelo vírus da COVID-19 e o aparecimento de lesões na cavidade bucal não possa ser estabelecida pelos estudos atualmente disponíveis, é provável que as lesões sejam associadas ao estado de imunossupressão, bem como o estresse, inerentes à COVID-19 (Diaz et al., 2020). Tomo et al. (2020) sugere que as manifestações orais em pacientes com COVID-19 podem ser consideradas transtornos secundários, não lesões primárias causadas diretamente pelo vírus.

Publicações recentes apontam uma associação das lesões de mucosa com danos orgânicos e/ou complicações (trombocitopenia, coagulação intravascular disseminada e inflamação sistêmica), em pacientes com COVID-19. Exames histopatológicos de biópsias de pacientes SARS-CoV-2 positivos revelaram um efeito trombótico na mucosa oral, levantando uma teoria vascular para explicar a patogênese dessas lesões (Tapia et al., 2020).

Pode-se observar que grande parte das manifestações bucais em pacientes acometidos pela COVID-19 são lesões leves, localizadas e de caráter transitório. Na maioria dos casos essas alterações se resolvem dentro de 3 a 21 dias por meio de medicação tópica, higiene oral, ou até mesmo espontaneamente (Santos et al., 2020).

\section{Conclusão}

Diversos relatos de casos reportam lesões de mucosa oral em pacientes com COVID-19, tornando evidente que existe uma relação entre a infecção pelo SARS-CoV-2 e o aparecimento destas alterações. As manifestações bucais são bastante variáveis em apresentação clínica, embora sejam mais comuns as alterações de paladar e as lesões ulceradas. Não foram constatadas diferenças estatísticas significativas entre homens e mulheres, embora as lesões sejam mais comuns em adultos. No entanto, ainda não está claro se elas são causadas diretamente pelo vírus ou se são manifestações secundárias da infecção. Portanto, mais estudos são necessários para avaliar os efeitos da infecção por SARS-CoV-2 sobre a mucosa oral e esclarecer a patogênese dessas lesões.

\section{Referências}

Aghzedeh, N., et al. (2020). Oral vesicles and acral erythema: report of a cutaneous manifestation of COVID-19. International Journal of Dermatology, 59, 1153-1154.

Biadsee, A., et al. (2020). Olfactory and Oral Manifestations of COVID-19: Related Symptoms - A Potential Pathway to Early Diagnosis. Otolaryngology Head and Neck Surgery, 163(4), 722-728.

Brandão, T. B., et al. (2020). Oral lesions in patients with SARS-CoV-2 infection: could the oral cavity be a target organ?. Oral Medicine, 131(2), 45-51.

Carreras-Presas, C. M., et al. (2020). Oral vesiculobullous lesions associated with SARS-CoV-2 infection. Oral Diseases, 00, 1-3.

Chaux-Bodard, A.G., et al. (2020). Oral manifestation of Covid-19 as an inaugural symptom?. J Oral Med Oral Surg., $26(18), 1$.

Chen, L., et al. (2020). Detection of SARS-CoV-2 in saliva and characterization of oral symptoms in COVID-19 patients. Cell Prolif., 53(12), 1-7.

Corchuelo, J. \& Ulloa, F. C. (2020). Oral manifestations in a patient with a history of asymptomatic COVID-19: Case report. International Journal of Infectious Diseases, 100, 154-157.

Filette, J. M. K. (2020) Coronavirus disease 2019-related Kawasaki-like disease in an adult: A case report. JAAD Case Reports, 6(8), 780-782.

Lechien, J. R., et al. (2020). Parotitis-like symptoms associated with COVID-19. Emerging Infectious Diseases, 26 (9), $2270-2271$.

Lima, C. M. A. O. (2020). Informações sobre o novo coronavírus (COVID-19). Radiol Bras., 53(2), 5-6. 
Research, Society and Development, v. 11, n. 1, e46811125240, 2022

(CC BY 4.0) | ISSN 2525-3409 | DOI: http://dx.doi.org/10.33448/rsd-v11i1.25240

Lowe, A., et al. (2021). COVID-19-associated herpetic gingivostomatitis. Clinical and Experimental Dermatology., 46, $162-194$.

Malih, N., et al. (2020). Unexpected Presentation of COVID-19 in a 38-Year-Old Male Patient: A Case Report. Case Rep Dermatol., 12 , $124-131$.

Medeiros, R. A., et al. (2020). Prevalence of symptoms of temporomandibular disorders, oral behaviors, anxiety, and depression in Dentistry students during the period of social isolation due to COVID-19. J Appl Oral Sci., 28, 1-8.

Miranda, J. S., et al. (2021). COVID-19 and Painful Temporomandibular Disorders: what does the dentist need to know?. RGO, Rev Gaúch Odontol., 69, 1-7.

Moraes, M. F., et al. (2021). Oral and cutaneous manifestations of covid-19 in pediatric patients. RGO, Rev Gaúch Odontol., 69, 05.

Nuno-Gonzalez, A., et al. (2021). Prevalence of mucocutaneous manifestations in 666 patients with COVID-19 in a field hospital in Spain: oral and palmoplantar findings. Br J Dermatol., 184, 184-5.

Orcina, B. F. \& Santos, P.S.S. (2021). Oral manifestation COVID-19 and the rapid resolution of symptoms post-Phtalox treatment: a case series. Int. J. Odontostomat., 15(1), 67-70.

Pedrosa, M. S., et al. (2020). Salivary glands, saliva and oral findings in COVID-19 infection. Pesqui Bras Odontopediatria Clín Integr., $20(1), 1-7$.

Rocha, B. A., et al. (2021). Viral enanthema in oral mucosa: A possible diagnostic challenge in the COVID-19 pandemic. Oral Diseases, 27(3), 776-778.

Rodríguez, M. D., et al. (2020). Oral manifestations associated with COVID-19. Oral Diseases, 00, 1-3.

Sandhaus, H., et al. (2020). Association Between COVID-19 and Kawasaki Disease: Vigilance Required From Otolaryngologists. Otolaryngology-Head and Neck Surgery, 163(2), 316-317.

Santos, J. A., et al. (2020). Oral Manifestations in Patients with COVID-19: A Living Systematic Review. Journal of Dental Research, 00(0), 1-14.

Sinadinos, A. \& Shelswell, J. (2020). Oral ulceration and blistering in patients with COVID-19. Evidence-Based Dentistry, $21,49$.

Singh, C., et al. (2020). Skin and Mucosal Damage in Patients Diagnosed With COVID-19. J Wound Ostomy Continence Nurs, 47(5), 435-438.

Soares, C. D., et al. (2020). Oral lesions in a patient with Covid-19. Med Oral Patol Oral Cir Bucal., 25, 4.

Tapia, R. O. C., et al. (2020). Oral mucosal lesions in patients with SARS-CoV-2 infection. Report of four cases. Are they a true sign of COVID-19 disease?. Spec Care Dentist., 40, 555-560.

Tomo, S., et al. (2020). Oral mucositis in a SARS-CoV-2-infected patient: Secondary or truly associated condition?. Oral Diseases, 00, 1-5. 